\title{
Therapeutic potential of PRL-3 targeting and clinical significance of $P R L-3$ genomic amplification in gastric cancer
}

Akira Ooki", Keishi Yamashita, Shiro Kikuchi, Shinichi Sakuramoto, Natsuya Katada, Mina Waraya, Hiroshi Kawamata, Hiroshi Nishimiya, Kazunori Nakamura and Masahiko Watanabe*

\begin{abstract}
Background: Phosphatase of regenerating liver-3 (PRL-3) has deserved attention as a crucial molecule in the multiple steps of metastasis. In the present study, we examined the mechanisms regulating PRL-3 expression, and assessed the clinical potential of PRL-3-targeted therapy in gastric cancer.

Methods: PRL-3 genomic amplification was analyzed using quantitative-polymerase chain reaction and/or fluorescence in situ hybridization in 77 primary gastric tumors. The anticancer activity of PRL-3 inhibitor (1-4bromo-2-benzylidene rhodanine) treatment was evaluated against cancer cells with different genetic and expression status.
\end{abstract}

Results: PRL-3 genomic amplification was closely concordant with high level of its protein expression in cell lines, and was found in 20\% (8/40) among human primary tumors with its expression, which were all stage III/IV disease $(40 \%, 8 / 20)$, but in none $(0 / 37)$ among those without expression. Additionally, PRL-3 genomic amplification was associated with metastatic lymph node status, leading to advanced stage and thereby poor outcomes in patients with lymph node metastasis $(P=0.021)$. PRL-3 small interfering RNA robustly repressed metastatic properties, including cell proliferation, invasion, and anchorage-independent colony formation. Although neither PRL-3 genomic amplification nor expression level was responsible for the sensitivity to PRL-3 inhibitor treatment, the inhibitor showed dose-dependent anticancer efficacy, and remarkably induced apoptosis on all the tested cell lines with PRL-3 expression.

Conclusions: We have for the first time, demonstrated that PRL-3 genomic amplification is one of the predominant mechanisms inducing its expression, especially in more advanced stage, and that PRL-3-targeted therapy may have a great potential against gastric cancer with its expression.

Keywords: PRL-3 gastric cancer, genomic amplification, targeted therapy, lymph node

\section{Background}

Gastric cancer (GC) is the fourth most common cancer and the second leading cause of cancer-related death worldwide [1]. Recent improvements in diagnostic tools and methods have facilitated detection of early GC and thereby excellent long-term survival. However, patients with advanced disease at the time of diagnosis remain poor outcomes. Metastasis is a multistep process, involving local invasion, dissemination, and re-establishment

\footnotetext{
*Correspondence: sp9y9tq9@piano.ocn.ne.jp; gekaw@med.kitasato-u.ac.jp Department of Surgery, Kitasato University Hospital, Kitasato 1-15-1, Sagamihara 228-8555, Kanagawa, Japan
}

into distant organs, and is the major determinant of the mortality [2]. Therefore, a better understanding of metastasis may open the way to a host of innovative therapeutic strategies in GC.

The protein tyrosine phosphatases (PTPs) form a large family of enzymes that serve as key regulatory components in signal transduction pathways [3]. The phosphatases of regenerating liver (PRL-1, -2 , and -3), belonging to a small class of PTP superfamily, have a unique $\mathrm{COOH}$-terminal prenylation motif, which critically affects their cellular localization and function [4]. PRL-3 was firstly identified to be specifically over-expressed in 
liver metastases derived from colorectal cancer [5], and subsequently its overexpression was documented in various tumor types, including GC [6]. PRL-3 can promote cancer invasion, migration, growth, and angiogenesis, through either dephosphorylation that is catalyzed by catalytic domain or localization to plasma membrane directed by $\mathrm{COOH}$-terminal prenylation motif [7-9]. Thus, PRL-3 has deserved attention as a crucial molecule in the multiple steps of metastasis and therefore as a new therapeutic target. On the other hand, the mechanisms inducing PRL-3 expression are not fully clarified. Amplification of genomic regions containing oncogenes is the major mechanism of its consequent overexpression and the cancer development, and therefore has importance for targeted therapies [10]. $P R L-3$ gene amplification partially accounts for the overexpression in colorectal cancer and esophageal cancer $[5,11]$. However, the relationship between genomic amplification and $\mathrm{GC}$ remains elusive in the both mechanistic and therapeutic points of view. In the present study, we examined the characteristics of $P R L-3$ genomic amplification in $\mathrm{GC}$, and further assessed the clinical potential of PRL-3-targeted therapy.

\section{Methods}

\section{Cell lines and Tissue Samples}

The GC cell line MKN7 was kindly provided from the Cell Resource Center for Biomedical Research Institute of Development, Aging and Cancer, Tohoku University (Sendai, Japan). Seven other GC cell lines (GCIY, AZ521, KatoIII, SH10, H111, MKN74, and NUGC4) were purchased from RIKEN BioResource Center (Ibaraki, Japan). These cell lines cover the two main types of GC [12], intestinal type (MKN7, MKN74, AZ521, and H111 cells) and diffuse type (GCIY, KatoIII, SH10, and NUGC cells) [13-15]. MKN7, NUGC4, and AZ521 cells were established from lymph node metastasis (LNM), and MKN74 cells were from liver metastasis. KATOIII and GCIY cells were established from metastatic pleural effusion and ascites, respectively. $\mathrm{H} 111$ and SH10 cells were established from the xenotransplantation. Normal skeletal muscle $\mathrm{C} 2 \mathrm{C} 12$ cells were purchased from DS Pharma Biomedical Co., Ltd (Osaka, Japan). AZ521 and C2C12 cells were grown in DMEM medium (GIBCO, Carlsbad, CA) supplemented with $10 \%$ fetal bovine serum (FBS). The other cells were grown in RPMI1640 medium (GIBCO) supplemented with 10\% FBS. 1-4bromo-2-benzylidene rhodanine was purchased from Calbiochem Corp (San Diego, CA), which was identified as a PRL-3 inhibitor through high throughput screening using chemical library of Korea Chemical Bank, and inhibited PRL-3 phosphatase activity [16]. Indeed, phosphorylation of KRT8, PRL-3-interacting protein, induced by catalytically inactive mutant of PRL-3, but not by wild type, was confirmed by PRL-3 inhibitor treatment in a dose-dependent manner [17]. Moreover, anticancer efficacy of PRL-3 inhibitor treatment also showed to be similar to that of siRNA treatment in esophageal cancer or colorectal cancer $[11,17]$.

Out of 173 formalin-fixed, paraffin-embedded, tissue samples series where we previously assessed PRL-3 expression status using immunohistochemical staining (IHC) in GC [6], 77 matched pairs of primary tumor tissues and the corresponding normal mucosa tissues were randomly selected from patients with differential stages according to the $13^{\text {th }}$ edition of the Japanese Classification of Gastric Carcinoma (JCGC) [18]; 40 pairs with positive PRL-3 expression (10 patients in Stage I, 10 in II, 10 in III, and 10 in IV) and 37 pairs with negative expression (10 patients in stage I, 10 in II, 9 in III, and 8 in IV). All patients underwent gastrectomy according to the gastric cancer treatment guidelines in Japan [19], and histopathologic examinations were done according to the JCGC. The $6^{\text {th }}$ edition of the International Union Against Cancer (UICC)/TNM classification was also used [20]. Table 1 depicts the detailed information on 77 patients. All tissue samples were collected at the Kitasato University Hospital, and informed consent was obtained from all patients. The present study was approved by the Ethics Committee of the Kitasato University.

\section{Fluorescence in situ hybridization analysis}

Fluorescence in situ hybridization (FISH) analysis was performed, as described previously [11]. PRL-3 is located on chromosome 8q24.3 (GenBank accession number NT 000008.9), and the chromosome 8 centromeric probe was used to estimate the copy number. Because PRL-3 FISH scoring algorithms had not been standardized, the assessment was based on the criteria of HER2 [21]. For each sample, at least 60 cancer cells were scored. Positive $P R L-3$ genomic amplification was defined as a ratio of $P R L-3$ to chromosome 8 centromere more than 2.2 , and negative was the ratio of less than 1.8. If the ratio of PRL-3 to chromosome 8 centromere was 1.8 to 2.2 , additional cells were counted, and the ratio of more than 2.0 was finally considered as positive [21]. Polysomy was defined as the mean chromosome 8 centromeric signals more than 3.0 per nucleus [22].

\section{Quantitative-genomic PCR}

Tissue sections from tumor and the corresponding normal mucosa, obtained at least $5 \mathrm{~cm}$ from the tumor edge, were sharply dissected on hematoxylin and eosinstained slides, and genomic DNA was subsequently extracted using of a QIAamp DNA FFPE Kit (QIAGEN Sciences, Hilden). Quantitative-genomic polymerase chain reaction (Q-PCR) was performed to quantify 
Table 1 Correlation between PRL-3 gene amplification and clinicopathological variables in 77 patients with gastric cancer

\begin{tabular}{|c|c|c|c|c|c|c|}
\hline \multirow{3}{*}{ Variables } & \multirow{3}{*}{ Total number } & \multicolumn{4}{|c|}{ PRL-3 gene amplification } & \multirow{3}{*}{$p$ value } \\
\hline & & \multicolumn{2}{|c|}{ Negativity } & \multicolumn{2}{|c|}{ Positivity } & \\
\hline & & Number & (\%) & Number & $(\%)$ & \\
\hline PRL-3 expression & & & & & & 0.006 \\
\hline Negativity & 37 & 37 & $(100)$ & 0 & $(0)$ & \\
\hline Positivity & 40 & 32 & $(80)$ & 8 & $(20)$ & \\
\hline Age (years) & & & & & & 0.726 \\
\hline$<60$ & 34 & 30 & (88) & 4 & $(12)$ & \\
\hline$\geq 60$ & 43 & 39 & (91) & 4 & (9) & \\
\hline Gender & & & & & & 0.710 \\
\hline Male & 51 & 45 & (88) & 6 & $(12)$ & \\
\hline Female & 26 & 24 & (92) & 2 & (8) & \\
\hline Lymphatic permeation & & & & & & 0.343 \\
\hline Absence & 15 & 15 & $(100)$ & 0 & (0) & \\
\hline Presence & 62 & 54 & $(87)$ & 8 & (13) & \\
\hline Vascular permeation & & & & & & 0.263 \\
\hline Absence & 25 & 24 & (96) & 1 & (4) & \\
\hline Presence & 52 & 45 & (87) & 7 & (13) & \\
\hline Differentiation & & & & & & 0.134 \\
\hline Well and moderate & 31 & 30 & (97) & 1 & (3) & \\
\hline Poor & 46 & 39 & (85) & 7 & $(15)$ & \\
\hline Depth of invasion & & & & & & $0.006^{*}$ \\
\hline $\mathrm{T} 1$ (m and $\mathrm{sm}$ ) & 15 & 15 & $(100)$ & 0 & $(0)$ & \\
\hline $\mathrm{T} 2$ (mp and ss) & 35 & 33 & (94) & 2 & (6) & \\
\hline T3 (se) & 19 & 16 & (84) & 3 & $(16)$ & \\
\hline T4 (si) & 8 & 5 & (63) & 3 & (38) & \\
\hline Lymph node metastasis & & & & & & 0.022 \\
\hline Absence & 29 & 29 & $(100)$ & 0 & $(0)$ & \\
\hline Presence & 48 & 40 & (83) & 8 & $(17)$ & \\
\hline JCGC lymph node status $^{\dagger}$ & & & & & & $0.004^{*}$ \\
\hline NO & 29 & 29 & $(100)$ & 0 & $(0)$ & \\
\hline N1 & 21 & 20 & (95) & 1 & (5) & \\
\hline $\mathrm{N} 2$ & 20 & 14 & (70) & 6 & (30) & \\
\hline N3 and distant lymph nodes & 7 & 6 & (86) & 1 & $(14)$ & \\
\hline UICC lymph node status $^{\ddagger}$ & & & & & & $0.002^{*}$ \\
\hline No & 29 & 29 & $(100)$ & 0 & $(0)$ & \\
\hline N1 & 18 & 17 & (94) & 1 & (6) & \\
\hline N2 & 16 & 13 & (81) & 3 & (19) & \\
\hline N3 and distant lymph nodes & 14 & 10 & (71) & 4 & $(29)$ & \\
\hline JCGC stage & & & & & & $0.005^{*}$ \\
\hline I (IA and IB) & 20 & 20 & $(100)$ & 0 & $(0)$ & \\
\hline$\|$ & 20 & 20 & $(100)$ & 0 & (0) & \\
\hline III (IIIA and IIIB) & 19 & 15 & $(79)$ & 4 & $(21)$ & \\
\hline IV & 18 & 14 & (78) & 4 & $(22)$ & \\
\hline UICC stage & & & & & & $0.003^{*}$ \\
\hline I (IA and IB) & 21 & 21 & $(100)$ & 0 & (0) & \\
\hline$\|$ & 20 & 20 & $(100)$ & 0 & (0) & \\
\hline III (IIIA and IIIB) & 16 & 13 & (81) & 3 & (19) & \\
\hline IV & 20 & 15 & (75) & 5 & $(25)$ & \\
\hline
\end{tabular}


PRL-3 gene copy numbers using $\mathrm{iQ}^{\mathrm{TM}}$ Supermix (Bio-Rad Laboratories, Hercules, CA) in triplicate on the iCycler $\mathrm{iQ}^{\mathrm{TM}}$ Real-Time PCR Detection system (Bio-Rad). To normalize $P R L-3$ gene copy number per cell, ADAM metallopeptidase domain 2 (ADAM2, NT 923907.1), located on chromosome 8 p11.2, was used as an endogenous reference because that gene amplification is defined as a copy number increase of a restricted region of a chromosome arm [10]. $\Delta \mathrm{Ct}$ values were calculated as $\mathrm{Ct}(P R L-3)-\mathrm{Ct}$ (ADAM2) for each sample. Relative copy number was determined as $2^{-\Delta \Delta C t}$, where $\Delta \Delta C_{t}=\Delta C_{t}$ (tumor) $-\Delta C_{t}$ (corresponding normal) [23]. The increases of more than 2 -fold relative to the corresponding normal were considered as genomic amplification. Additional file 1 depicts detailed PCR condition and sequences of primer and probe used in the present study.

\section{Western blotting}

Whole cell lysates were extracted in RIPA buffer (Pierce, Rockford, IL) supplemented with $10 \mu \mathrm{L} / \mathrm{mL}$ Halt ${ }^{\mathrm{TM}}$ Protease Inhibitor Cocktail Kit (Pierce) and Halt ${ }^{\mathrm{TM}}$ Phosphatase Inhibitor Cocktail Kit (Pierce), and the protein were separated on NuPAGE ${ }^{\circledR}$ 4-12\% Bis-Tris Gel (Invitrogen) according to the manufacturer's protocol. Both detection and quantification of the specific proteins were performed using ATTO Light Capture (ATTO Corporation, Tokyo, Japan). Two colorectal cancer cell lines DLD-1 and SW480 cells (RIKEN BioResource) were used as the low and high expression controls, respectively, as described previously [11].

PRL-3 mouse monoclonal antibody (R\&D Systems, Minneapolis, $\mathrm{MN}$ ) and $\beta$-actin mouse monoclonal antibody (Sigma, St. Louis, MO) were used as described previously [11].

\section{PRL-3 small interfering RNA transfection}

Cells were transfected with $1 \mu \mathrm{mol} / \mathrm{L}$ Accell SMARTpool, siRNA-PRL-3 (Thermo Fisher Scientific, Lafayette, CO) mixed with Accell siRNA Delivery Media (Thermo Fisher Scientific) according to the Thermo Scientific Dharmacon $^{\circledR}$ Accell ${ }^{\mathrm{TM}}$ siRNA Delivery Protocol [24]. The Accell Non-targeting Pool (siRNA-ctr) and Accell siRNA Delivery Media alone were used as a control for non-sequence-specific effects and as a mock-treatment, respectively.

\section{Anchorage-independent colony formation assay}

Anchorage-independent cell growth was analyzed by plating $0.36 \%$ top agarose (Bacto $^{\mathrm{TM}}$ Agar, Becton, Dickinson and Company, Franklin Lakes, NJ) containing $1 \times$ $10^{5}$ cells on a surface of $0.72 \%$ bottom agarose in 6 -well plates [11]. Cells were fed weekly by overlying fresh soft-agar solution, and colonies were photographed after 2 weeks of incubation. The $50 \%$ effective concentration
$\left(\mathrm{EC}_{50}\right)$ value of PRL-3 inhibitor treatment was calculated based on the measurement of colony count.

\section{Proliferation assay and invasion assay}

The proliferation assay was performed using Premix WST-1 Cell Proliferation Assay System (Takara Bio, Tokyo). Cells $\left(2 \times 10^{3}\right)$ were seeded in 96-well, and the proliferative activity was measured by absorbance at $450 \mathrm{~nm}$ on designated sampling days. The sensitivity to PRL-3 inhibitor on antiproliferation was determined using the $50 \%$ inhibitory concentration $\left(\mathrm{IC}_{50}\right)$ value after treatment for 72 hours.

The invasion assay was performed in the 24-well BD BioCoat $^{\mathrm{TM}}$ Matrigel ${ }^{\mathrm{TM}}$ Invasion Chamber (BD Biosciences Discovery Labware, Bedford, MA). Cells that had invaded through the membrane were counted in four separated fields per well. Both experiments were done in triplicate.

\section{Apoptosis Assays}

Apoptosis assays were performed using Guava PCA System (Guava Technologies, Inc., Hayward, CA). Cells $\left(2 \times 10^{5}\right)$ were treated with the PRL-3 inhibitor at the indicated concentration in medium supplemental with 1.0\% FBS for 72 hours, then stained with Annexin V and 7-AAD (Guava Nexin Reagent). The experiment was done in triplicate and analyzed using CytoSoft 2.1.5 software (Guava Technologies).

\section{Statistical Analysis}

Fisher's exact test, or the Mann-Whitney $U$-test was used to statistically analyze the relationship between $P R L-3$ gene amplification and clinicopathological variables. One-way analysis of variance (ANOVA) with post-hoc test was used to compare between three groups for siRNA treatment (siRNA-PRL-3, siRNA-ctr, and mock). Student $t$ test was used to evaluate therapeutic effect for the individual concentrations of PRL-3 inhibitor, compared with $0 \mu \mathrm{mol} / \mathrm{L}$ of PRL-3 inhibitor. The Kaplan-Meier method was used to estimate cumulative survival rates, and differences in survival rates were assessed with the use of the log-rank test. All deaths of patients were cancer-related, and disease specific survival (DSS) was measured from the date of surgery to the date of death or the last follow-up. $P<0.05$ was considered to indicate statistical significance. All statistical analyses were conducted with JMP 7.0 software (SAS Institute, Cary, NC).

\section{Results}

PRL-3 expression and genomic amplification in gastric cancer cell lines

Initially, PRL-3 expression status was evaluated using western blotting in $8 \mathrm{GC}$ cell lines (Figure 1A). PRL-3 


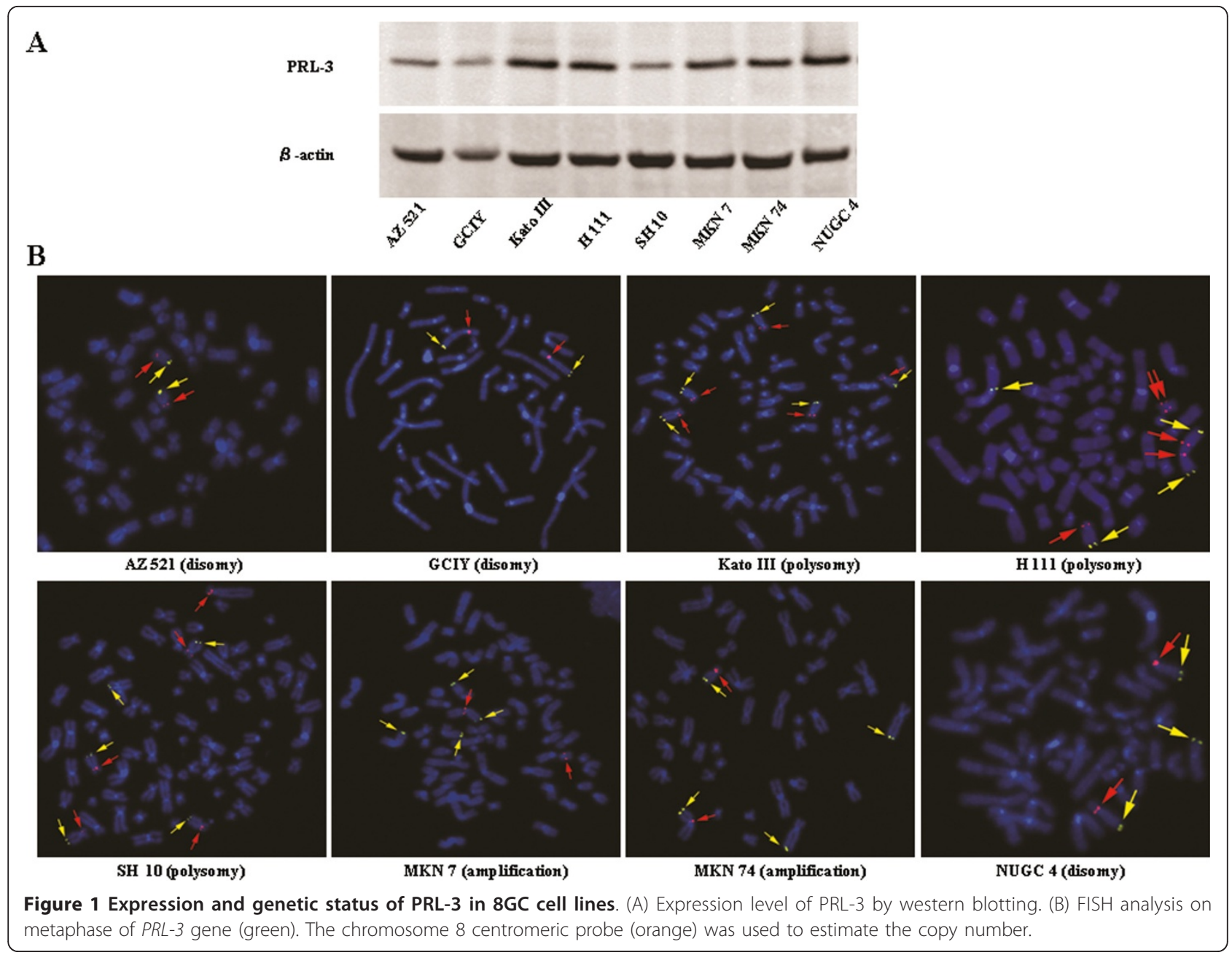

expression was observed at a detectable level in all the cell lines, among which 5 cell lines (KatoIII, H111, MKN7, MKN74, and NUGC4 cells) and 3 cell lines (GCIY, AZ521, and SH10 cells) exhibited high and relatively low expression, respectively. Subsequently, FISH analysis was performed to examine whether PRL-3 expression was caused through its genomic amplification (Figure 1B). Genomic amplification was obviously positive in 2 cell lines (MKN7 and MKN74 cells) and negative in 6 cell lines. 3 of the six were dysomic (AZ521, GCIY, and NUGC4 cells), and three were polysomic (KatoIII, SH10, and H111 cells). PRL-3 genomic amplification frequently occurred in the different regions from chromosome 8 , so-called distributed insertions, on metaphase [10], and was concordant with its high expression.

\section{Characteristic of $P R L-3$ genomic amplification in human primary gastric cancers}

In our previous study, PRL-3 expression was detected in 95 (55\%) out of 173 primary GCs by IHC [6]. To explore the link between PRL-3 expression and its genomic amplification, Q-PCR was performed for both the 40 tumors with positive PRL-3 expression and 37 tumors with negative expression, which were randomly selected from differential stages in the 173 primary tumors. All the primary tumors without PRL-3 expression were not amplified, whereas 8 (20\%) out of the 40 primary tumors with PRL-3 expression were amplified (Figure 2A). FISH analyses also confirmed obvious genomic amplification as the cancerspecific alteration (Figure 2B), and exhibited at nearly homogenous pattern in both the central area and invasive area within tumor. Subsequently, the relationship with clinicopathological factors was assessed for $P R L-3$ genomic amplification (Table 1), where it was significantly associated not only with its expression $(P=0.006)$, but also with depth of tumor invasion $(P=0.006)$, presence of LNM $(P=0.022)$, LNM status $(P=0.004$ in JCGC, $P=$ 0.002 in UICC), and stage ( $P=0.005$ in JCGC, $P=0.003$ in UICC). Additionally, all the primary tumors with genomic amplification were stage III or IV disease $(40 \%, 8 / 20)$. Moreover, the genomic amplification negatively affected 


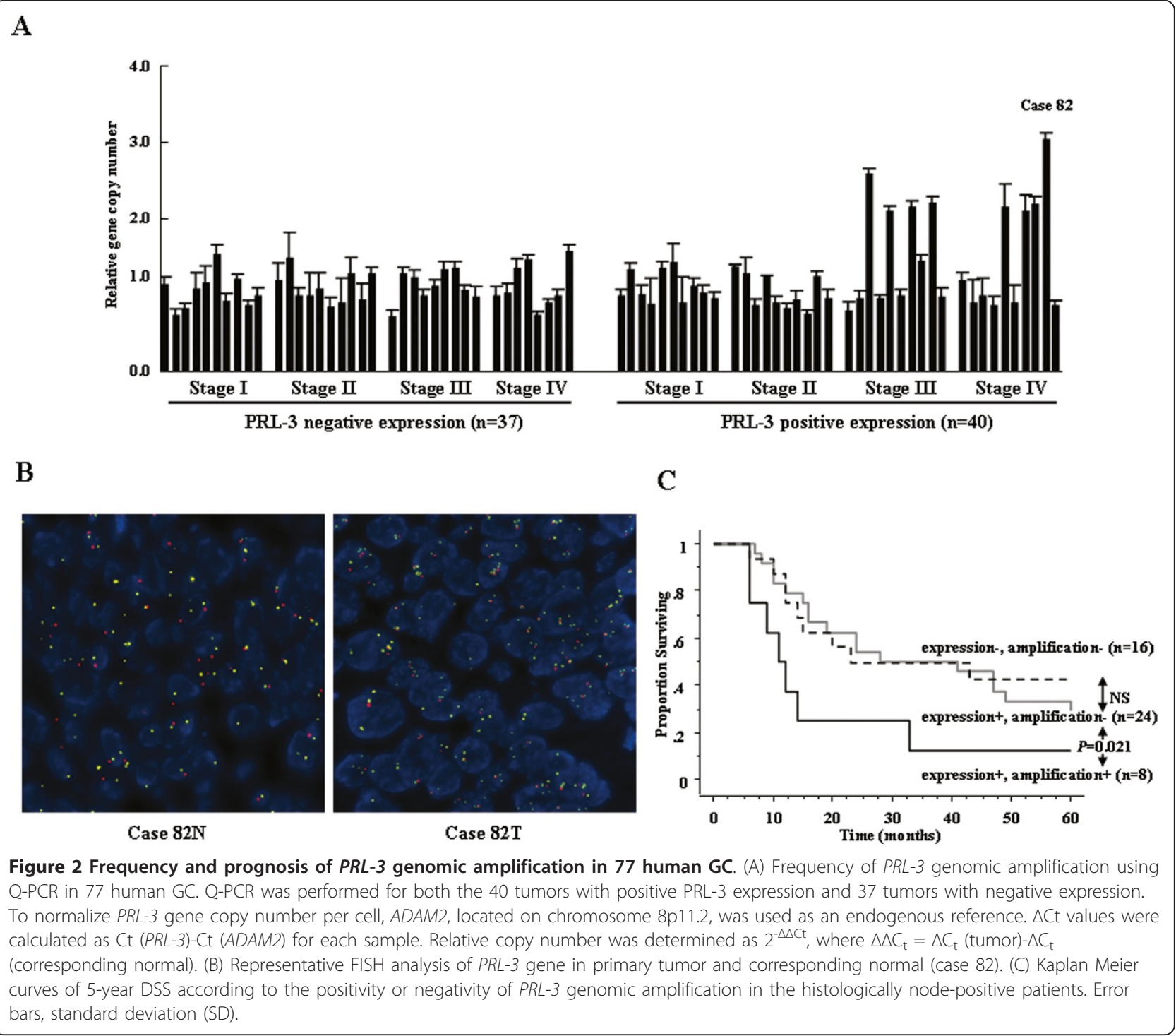

the outcomes of the histologically node-positive patients $(P=0.021$, Figure $2 C)$, although PRL-3 expression did not in our and other previous reports $[6,25]$.

\section{PRL-3 as a convergent therapeutic target}

In $\mathrm{GC}$, the functional roles of PRL-3, including invasion and proliferation abilities, have been documented only in SGC7901 cells [25]. To confirm these metastatic properties using 3 cell lines with different PRL-3 expression and genetic status, knock-down of endogenous PRL-3 expression was performed using siRNA transfection; AZ521 cells (low expression and disomy), H111 cells (high expression and polysomy), MKN74 cells (high expression and genomic amplification). These cell lines were transfected with siRNA-PRL-3 or siRNA-ctr, and western blotting showed the decreased level of PRL-3 protein in siRNA-PRL-3 cells, but not siRNA-ctr cells, compared with mock- treatment cells (Figure 3A). One of the important characteristic of the metastatic phenotype is supposed as the ability for cancer cells to grow under anchorage-independent conditions [26], but the involvement in PRL-3 remains unknown in GC. All siRNA-PRL-3 cells showed the significantly decreased size and number of colonies, compared to siRNA-ctr cells or mock-treatment cells (Figure $3 \mathrm{~B})$. Moreover, in line with previous reports for other GC cell lines [25,27], we also confirmed that siRNA-PRL-3 cells showed the significantly less proliferative activity (Figure 3C) and invasive ability (Figure 3D).

Therapeutic potential of PRL-3 inhibitor, 1-4-bromo-2benzylidene rhodanine

To assess the therapeutic potential and examine a landmark guiding the response to PRL-3-targeted therapy, we evaluated the anticancer activity of PRL-3 inhibitor, 


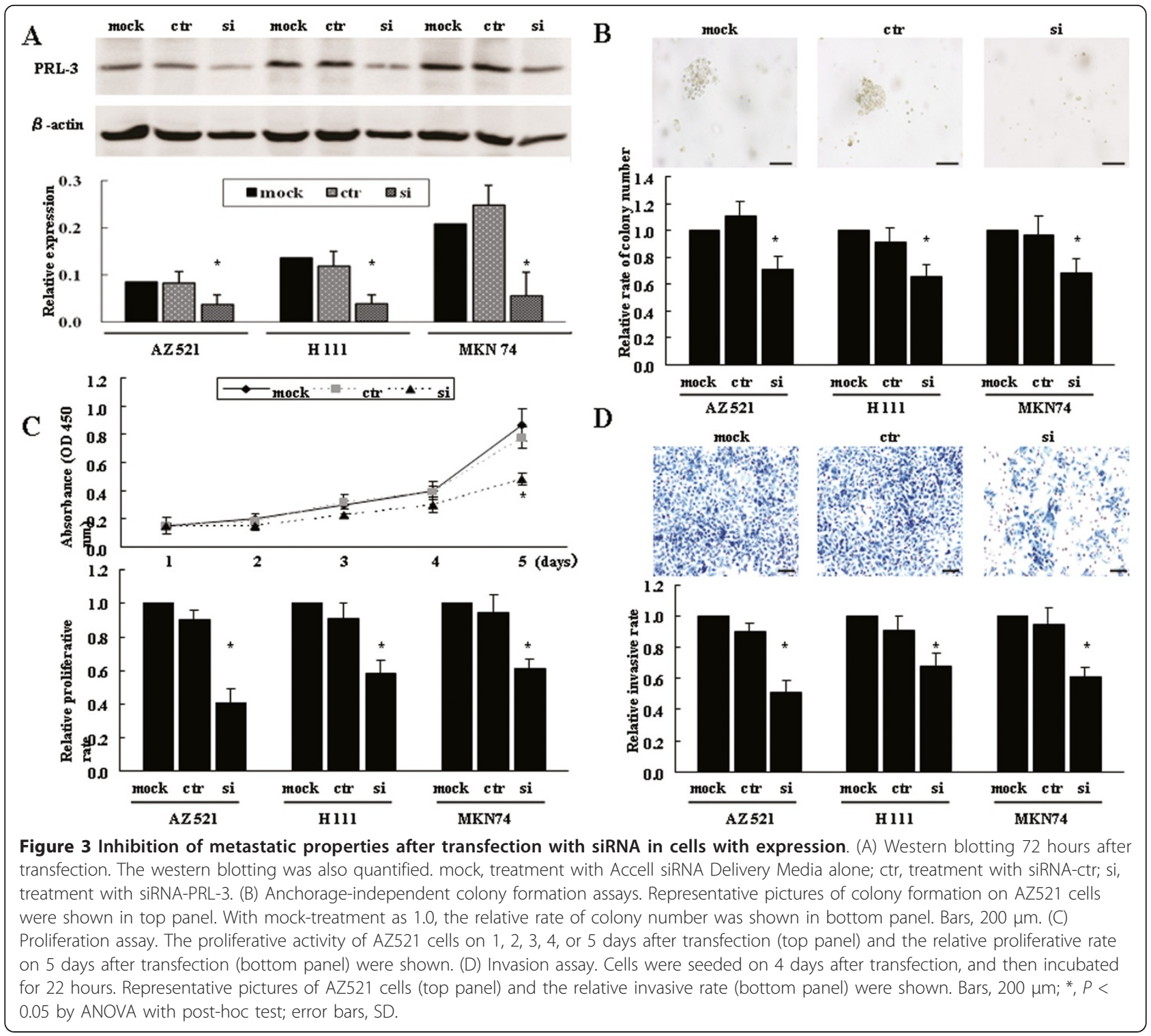

cell-permeable benzylidene rhodanine compound [16], against 6 cell lines with different PRL-3 expression and genetic status; GCIY and AZ521 cells (low expression and disomy), KatoIII cells (high expression and polysomy), SH10 cells (low expression and polysomy), MKN7 and MKN74 cells (high expression and genomic amplification). Cells were treated with PRL-3 inhibitor at concentrations ranging from 0 to $50 \mu \mathrm{mol} / \mathrm{L}$. PRL-3 inhibitor showed dose- and time-dependent antiproliferative efficacy on all the tested cell lines, irrespective of different PRL-3 expression level and genetic status, and the $\mathrm{IC}_{50}$ values of GCIY, AZ521, KatoIII, SH10, MKN7, and MKN74 cells were 26.77, 9.98, 24.26, 23.95, 22.29 , and $9.45 \mu \mathrm{mol} / \mathrm{L}$, respectively (Figure $4 \mathrm{~A}$ ). AZ521 and MKN74 cells were more sensitive to PRL-3 inhibitor treatment than GCIY and MKN7 cells that were categorized as the identical groups in terms of expression and genetic status, respectively. Namely, genetic or expression status was not associated with sensitivity of GC cells against the PRL-3 inhibitor. Similar efficacy was shown in anchorage-independent colony formation, and the $\mathrm{EC}_{50}$ values of GCIY, AZ521, SH10, and MKN74 cells were 6.99, 9.52, 13.05, $9.09 \mu \mathrm{mol} / \mathrm{L}$, respectively (Figure 4B). GCIY cells exhibited more sensitive inhibition in contrast with the anti-proliferation. Additionally, this inhibitor also robustly abrogated the invasive ability of GC cells (Figure 4C). To further characterize the anticancer efficacy of PRL-3 inhibitor treatment, apoptosis assay was performed (Figure 5A). Although $1 \mu \mathrm{mol} / \mathrm{L}$ of the inhibitor was insufficient to induce apoptosis beyond the baseline $(0 \mu \mathrm{mol} / \mathrm{L})$, $10 \mu \mathrm{mol} / \mathrm{L}$ of the inhibitor robustly caused the drastic 


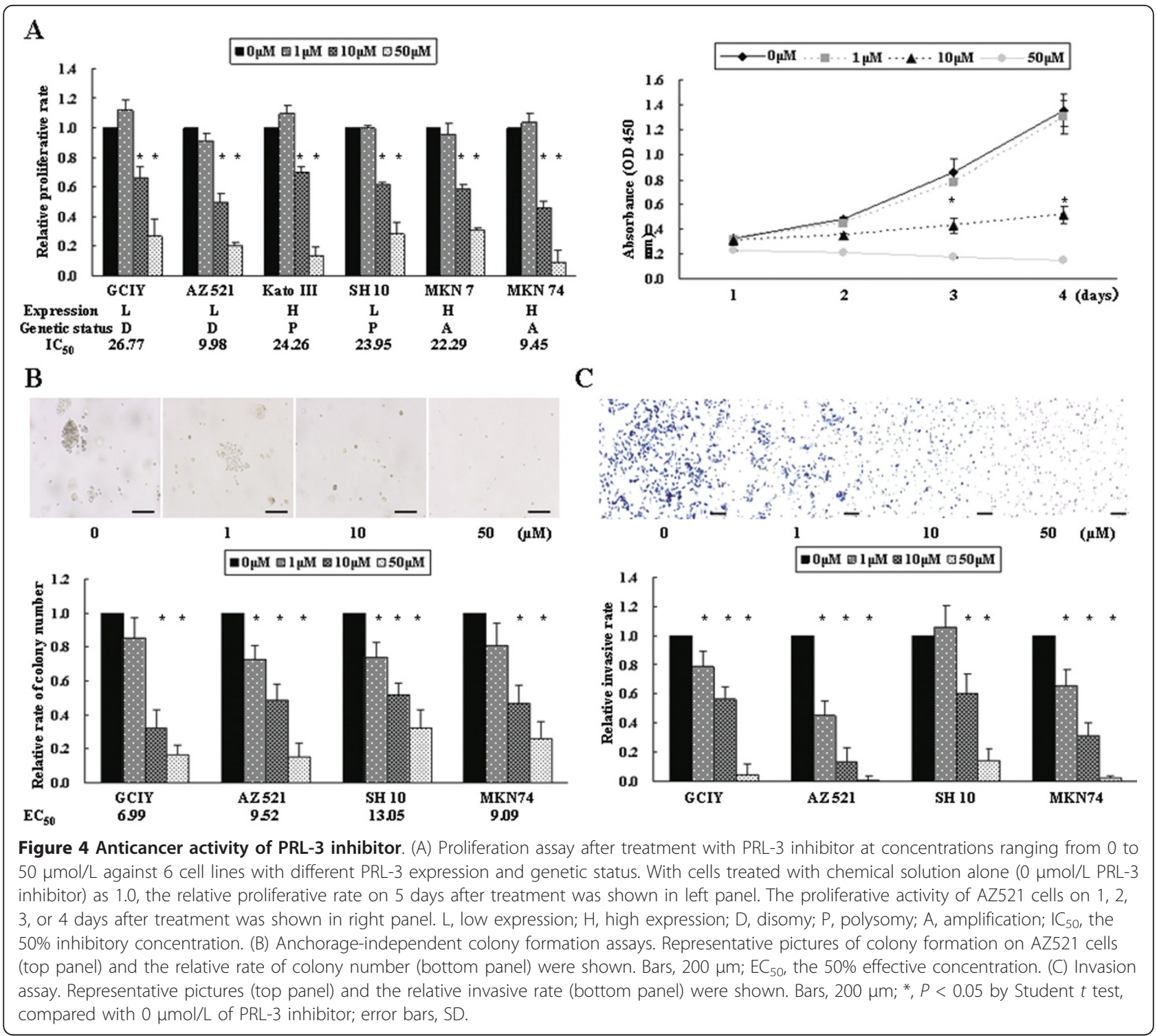

apoptosis on all the tested cell lines, where there were the 3-fold and 11-fold increases beyond the baseline in GCIY and MKN74 cells, respectively. Thus, PRL-3 inhibitor repressed these metastatic properties on all the tested cell lines in dose-dependent manner, and neither expression level nor genetic status showed clear correlation with the sensitivity.

Finally, we assessed whether PRL-3 inhibitor induced cytotoxicity in normal skeletal muscle, where PRL-3 is predominantly expressed [28]. Both proliferation and apoptosis assays were performed using normal skeletal muscle $\mathrm{C} 2 \mathrm{C} 12$ cells treated with the inhibitor, and showed that $10 \mu \mathrm{mol} / \mathrm{L}$ of the inhibitor failed to cause antiproliferative and apoptotic response on $\mathrm{C} 2 \mathrm{C} 12$ in contrast with the efficacies on all the tested GC cell lines (Figure 5A and 5B).

\section{Discussion}

As LNM is considered as an important prognostic factor for GC [29], research of the causative molecules reflecting LNM is a promising avenue to improve the outcomes. The close link of LNM with PRL-3 expression, therefore, has potential as a new therapeutic target $[6,25]$. However, the criteria for PRL-3-targeted therapy have not been established, and it is critical to clarify the characteristics of $P R L-3$ genomic amplification in the both mechanistic and therapeutic points of view, because of the major mechanism of its consequent expression and the cancer development [10]. In the present study, we offer the vital clues for the development of this therapeutic strategy against GC.

The relationship between PRL-3 expression and its genomic amplification have never been examined so far. 


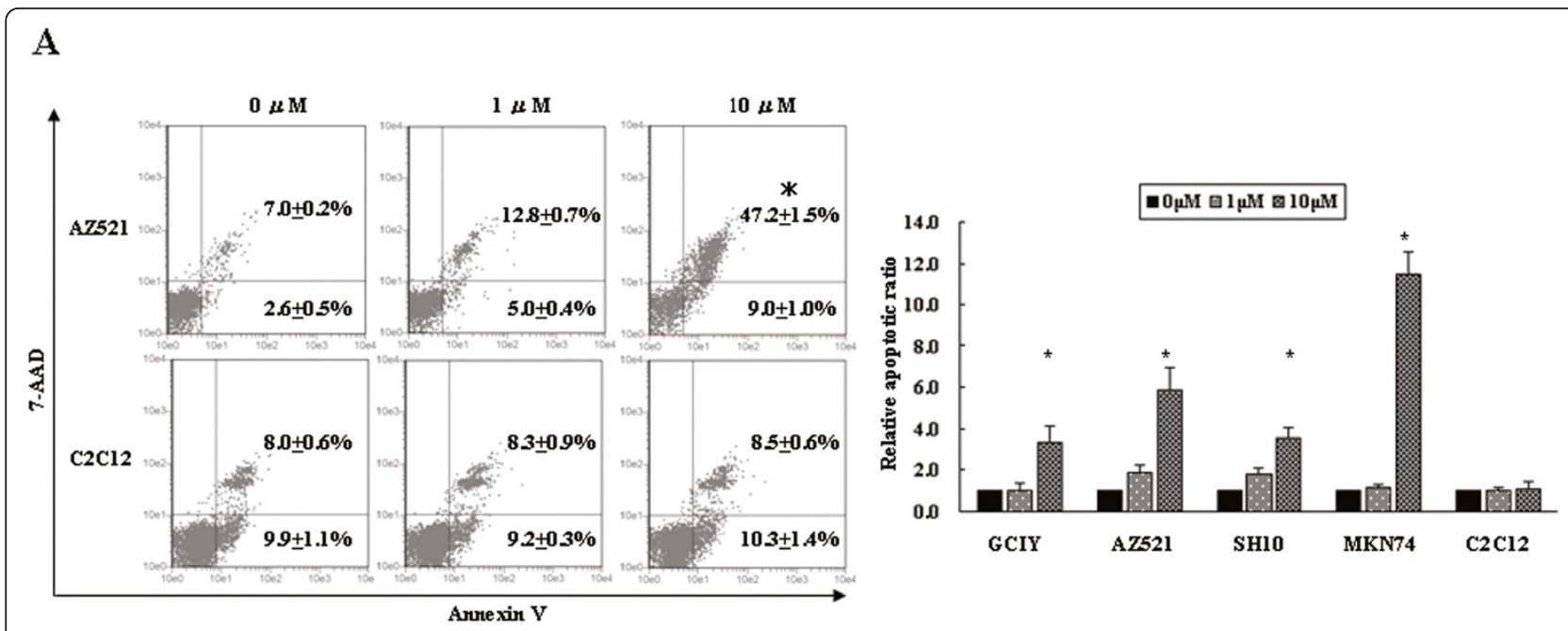

B
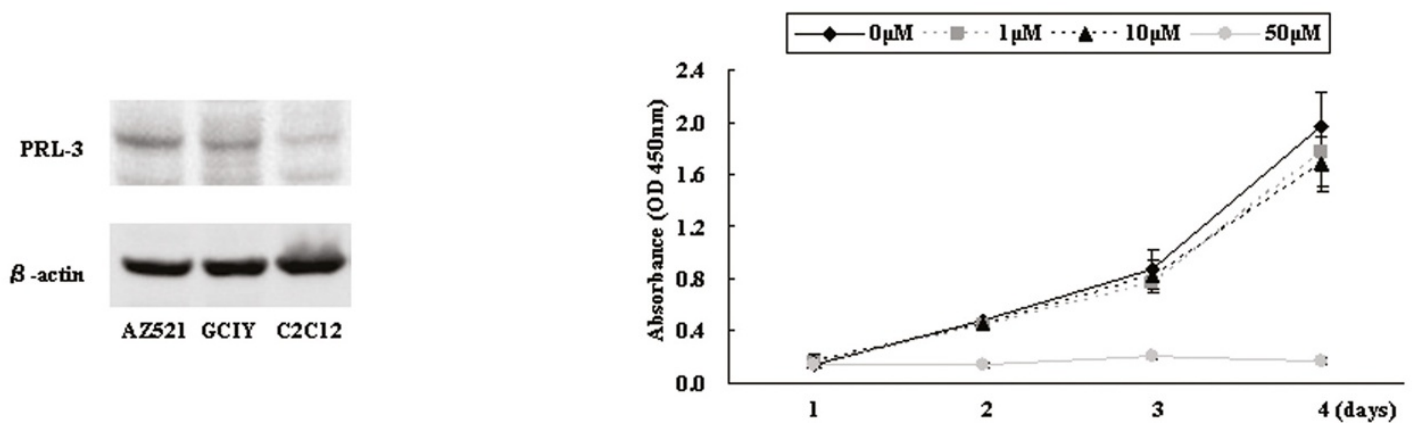

Figure 5 PRL-3 inhibitor-mediated apoptosis. (A) Apoptosis assay was performed 72 hours after treatment with PRL-3 inhibitor (0 to $10 \mu$ mol/ L). Representative figures of apoptosis assay on AZ521 and C2C12 cells were shown in left panel, and the percentage and SD of early apoptosis (bottom right quadrant) and late apoptosis (top right quadrant) are shown in each panel. With cells treated with chemical solution alone (0 $\mu \mathrm{mol} / \mathrm{L}$ PRL-3 inhibitor) as 1.0, the relative late apoptosis rate after treatment was shown in right panel. ${ }^{*}, P<0.05$ by Student $t$ test, compared with $0 \mu \mathrm{mol} / \mathrm{L}$ of PRL-3 inhibitor. (B) PRL-3 inhibitor treatment against normal skeletal muscle C2C12 cells. C2C12 cells exhibited lower expression level of PRL-3 than GC cells by western blotting. Proliferation assay after treatment with PRL-3 inhibitor was performed. Error bars, SD.

PRL-3 genomic amplification was concordant with its expression status in cell lines, and was found in 20\% (8/ 40) among human primary tumors with expression, which were all stage III or IV disease $(40 \%, 8 / 20)$, but in none $(0 / 37)$ among those without expression. Additionally, PRL-3 genomic amplification was associated with LNM status, leading to advanced stage and thereby poor outcomes in patients with LNM $(P=0.021)$. Thus, $P R L-$ 3 genomic amplification may be the more relevant alteration for LNM, and be one of the predominant mechanisms inducing its expression in the more advanced stage. However, most tumors expressing PRL3 were not amplified, especially in the earler stage. In mouse embryonic fibroblast cells with wild type but not $\mathrm{p} 53^{-1-}, \mathrm{PRL}-3$ is induced in a p53-dependent manner [30]. The p53 mutation or loss of function, however, has been documented in all the GC cell lines used in the present study, except for NUGC4 cells (The TP53 Web Site, http://p53.free.fr/), indicating that there is other mechanism independently of p53 pathway. PRL-3 expression was reported to be regulated at transcriptional level by mitogenic cytokines, such as IL-6, IL-21, HGF or IGF-1 in myeloma cell lines [24], or as TGF- $\beta$ in colon cancer cell lines [31]. Recently, PolyC-RNAbinding protein 1 (PCBP1) has been identified as a translational regulator of PRL-3 [32]. The alternative mechanisms at transcriptional or translational level may be involved to regulate PRL-3 expression.

We also confirmed that siRNA-mediated PRL-3 knockdown significantly repressed cell proliferation and invasion in line with previous reports for other GC cell lines [25,27], and furthermore for the first time revealed the reduced effect of colony formation under anchorage-independent conditions, supporting that PRL-3 
may be attractive therapeutic target against GC. The success of molecular-targeted therapy depends on the identification of a landmark to select patients with more benefit from the therapy, such as activating mutation or gene amplification of EGFR in non-small cell lung cancer [33], and overexpression or gene amplification of HER2 in breast cancer [34]. Thus, genetic alteration or expression status is possible to be a landmark for molecular-targeted therapy, and it is indispensable to evaluate the anticancer activity of PRL-3 inhibitor treatment against cancer cells with different genetic and expression status. Although neither PRL-3 genomic amplification nor expression level was responsible for the sensitivity to PRL-3 inhibitor treatment, the inhibitor exhibited dose-dependent efficacy on all the tested cell lines with PRL-3 expression, and remarkably induced apoptosis in line with a previous report [35]. PRL-3 is not expressed in human adult stomach, and its expression is cancerspecific event [6,7]. Collectively, the presence of PRL-3 expression, but not expression level, may be sufficient to promote metastatic properties through activation of downstream signaling pathways, and the effective inhibition seems to have important implication for the success of this treatment. Combined with our previous findings demonstrating the high frequency of PRL-3 expression (55\%, 95/173) [6], PRL-3-targeted therapy may be applicable for most patients with GC. The different sensitivity against PRL-3 targeting as shown in the present study may imply the additional alterations attenuating the dependence of PRL-3 signaling networks on cancer cells. Therefore, identification of molecules leading to the different sensitivity would shed light on the development of more sophisticated strategy.

Normal tissues with PRL-3 expression may be susceptible to adverse effects from the targeted therapy, especially in normal skeletal muscle and heart [28]. Interestingly, PRL-3 inhibitor treatment with the concentration of $10 \mu \mathrm{mol} / \mathrm{L}$ significantly repressed proliferation through apoptosis induction on all the tested GC cell lines, whereas did not on normal skeletal muscle $\mathrm{C} 2 \mathrm{C} 12$ cells, implying that this concentration may act as an optimal dose of anticancer activity without severe effects against muscle cells, and normal cells may have a better apoptotic protective mechanism, even though PRL-3 is constitutively expressed [35]. As C2C12 cells might not be the best control because of relatively weak expression, further research will be necessary to validate our findings.

\section{Conclusions}

We have for the first time demonstrated that $P R L-3$ genomic amplification is one of the predominant mechanisms inducing its expression, especially in more advanced stage, and that PRL-3-targeted therapy may have a great potential against gastric cancer with its expression.

\section{List of Abbreviations used}

PRL-3: Phosphatase of regenerating liver-3; GC: gastric cancer; PTP: protein tyrosine phosphatase; JCGC: Japanese Classification of Gastric Carcinoma; UICC: the Union Internationale Contre Le Cancer; FISH: fluorescence in situ hybridization; Q-PCR: quantitative-genomic polymerase chain reaction; $\mathrm{EC}_{50}$ : $50 \%$ effective concentration; $I_{50}$ : 50\% inhibitory concentration; ANOVA: analysis of variance; DSS: disease specific survival.

\section{Acknowledgements}

This work was supported in part by the Grant-in-Aid for Cancer Research from the Ministry of Health, Labour and Welfare of Japan and by the Japanese Foundation for Multidisciplinary Treatment of Cancer. The funding agencies had no role in the design of the study, data collection, or analysis; in the interpretation of the results; in the preparation of the manuscript; or in the decision to submit the manuscript for publication.

\section{Authors' contributions}

AO conceived of the study, performed the study, drafted the manuscript and participated in coordination. KY participated in coordination and assisted in editing of manuscript. SK, SS, NK, MW, HK, and KN helped in the collection and analysis of clinical data. MW participated in coordination. All authors read and approved the final manuscript.

\section{Competing interests}

The authors declare that they have no competing interests.

Received: 26 September 2010 Accepted: 6 April 2011 Published: 6 April 2011

\section{References}

1. Crew KD, Neugut Al: Epidemiology of gastric cancer. World I Gastroenterol 2006, 12(3):354-362.

2. Pantel K, Brakenhoff RH: Dissecting the metastatic cascade. Nat Rev Cancer 2004, 4:448-456.

3. Bessette DC, Qiu D, Pallen CJ: PRL PTPs: mediators and markers of cancer progression. Cancer Metastasis Rev 2008, 27:231-252.

4. Zeng Q, Si X, Horstmann H, Xu Y, Hong W, Pallen CJ: Prenylationdependent association of protein-tyrosine phosphatases PRL-1, -2, and -3 with the plasma membrane and the early endosome. J Biol Chem 2000, 275(28):21444-21452.

5. Saha S, Bardelli A, Buckhaults P, Velculescu VE, Rago C, St Croix B, Romans KE, Choti MA, Lengauer C, Kinzler KW, et al: A phosphatase associated with metastasis of colorectal cancer. Science 2001, 294(5545):1343-1346.

6. Ooki A, Yamashita K, Kikuchi S, Sakuramoto S, Katada N, Watanabe M: Phosphatase of regenerating liver-3 as a prognostic biomarker in histologically node-negative gastric cancer. Oncol Rep 2009, 21(6):1467-1475.

7. Guo K, Li J, Wang H, Osato M, Tang JP, Quah SY, Gan BQ, Zeng Q: PRL-3 initiates tumor angiogenesis by recruiting endothelial cells in vitro and in vivo. Cancer Res 2006, 66(19):9625-9635.

8. Song R, Qian F, Li YP, Sheng X, Cao SX, Xu Q: Phosphatase of regenerating liver-3 localizes to cyto-membrane and is required for B16F1 melanoma cell metastasis in vitro and in vivo. PLoS One 2009, 4(2):e4450.

9. Zeng Q, Dong JM, Guo K, Li J, Tan HX, Koh V, Pallen CJ, Manser E, Hong W: PRL-3 and PRL-1 promote cell migration, invasion, and metastasis. Cancer Res 2003, 63(11):2716-2722.

10. Albertson DG: Gene amplification in cancer. Trends Genet 2006, 22(8):447-455.

11. Ooki A, Yamashita K, Kikuchi S, Sakuramoto S, Katada N, Watanabe M: Phosphatase of regenerating liver-3 as a convergent therapeutic target for lymph node metastasis in esophageal squamous cell carcinoma. Int $J$ Cancer 2010, 127(3):543-554.

12. Lauren P: The Two Histological Main Types of Gastric Carcinoma: Diffuse and So-Called Intestinal-Type Carcinoma. an Attempt at a Histo-Clinical Classification. Acta Pathol Microbiol Scand 1965, 64:31-49.

13. Dote H, Toyooka S, Tsukuda K, Yano M, Ota T, Murakami M, Naito M, Toyota M, Gazdar AF, Shimizu N: Aberrant promoter methylation in human DAB2 interactive protein (hDAB2IP) gene in gastrointestinal tumour. Br J Cancer 2005, 92(6):1117-1125. 
14. Nozue M, Nishida M, Todoroki T, Iwasaki Y: Establishment and characterization of a human scirrhus type gastric cancer cell line, GCIY, producing CA19-9. Hum Cell 1991, 4(1):71-75.

15. Yokozaki H: Molecular characteristics of eight gastric cancer cell lines established in Japan. Pathol Int 2000, 50(10):767-777.

16. Ahn JH, Kim SJ, Park WS, Cho SY, Ha JD, Kim SS, Kang SK, Jeong DG, Jung SK, Lee SH, et al: Synthesis and biological evaluation of rhodanine derivatives as PRL-3 inhibitors. Bioorg Med Chem Lett 2006, 16(11):2996-2999.

17. Mizuuchi E, Semba S, Kodama Y, Yokozaki H: Down-modulation of keratin 8 phosphorylation levels by PRL-3 contributes to colorectal carcinoma progression. Int I Cancer 2009, 124(8):1802-1810.

18. Association JGC: Japanese Classification of Gastric Carcinoma - 2nd English Edition. Gastric Cancer 1998, 1(1):10-24.

19. Nakajima T: Gastric cancer treatment guidelines in Japan. Gastric Cancer 2002, 5(1): :-5.

20. Sobin LH: TNM, sixth edition: new developments in general concepts and rules. Semin Surg Oncol 2003, 21(1):19-22.

21. Wolff AC, Hammond ME, Schwartz JN, Hagerty KL, Allred DC, Cote RJ, Dowsett M, Fitzgibbons PL, Hanna WM, Langer A, et al: American Society of Clinical Oncology/College of American Pathologists guideline recommendations for human epidermal growth factor receptor 2 testing in breast cancer. J Clin Oncol 2007, 25(1):118-145.

22. Baehner FL, Achacoso N, Maddala T, Shak S, Quesenberry CP Jr, Goldstein LC, Gown AM, Habel LA: Human epidermal growth factor receptor 2 assessment in a case-control study: comparison of fluorescence in situ hybridization and quantitative reverse transcription polymerase chain reaction performed by central laboratories. $J$ Clin Oncol 2010, 28(28):4300-4306

23. Livak KJ, Schmittgen TD: Analysis of relative gene expression data using real-time quantitaitve PCR and the 2(-Delta Delata $C(T))$ Method. Methods 2001, 25:402-408.

24. Fagerli UM, Holt RU, Holien T, Vaatsveen TK, Zhan F, Egeberg KW, Barlogie B, Waage A, Aarset H, Dai HY, et al: Overexpression and involvement in migration by the metastasis-associated phosphatase PRL-3 in human myeloma cells. Blood 2007, 111:806-815.

25. Wang Z, He YL, Cai SR, Zhan WH, Li ZR, Zhu BH, Chen CQ, Ma JP, Chen ZX, Li W, et al: Expression and prognostic impact of PRL-3 in lymph node metastasis of gastric cancer: its molecular mechanism was investigated using artificial microRNA interference. Int I Cancer 2008, 123(6):1439-1447.

26. Mori S, Chang JT, Andrechek ER, Matsumura N, Baba T, Yao G, Kim JW, Gatza M, Murphy S, Nevins JR: Anchorage-independent cell growth signature identifies tumors with metastatic potential. Oncogene 2009, 28:2796-2805.

27. Wang Z, Cai SR, He YL, Zhan WH, Chen CQ, Cui J, Wu WH, Wu H, Song W, Zhang $\mathrm{CH}$, et al: High expression of PRL-3 can promote growth of gastric cancer and exhibits a poor prognostic impact on patients. Ann Surg Oncol 2009, 16(1):208-219.

28. Matter WF, Estridge T, Zhang C, Belagaje R, Stancato L, Dixon J, Johnson B, Bloem L, Pickard T, Donaghue M, et al: Role of PRL-3, a human musclespecific tyrosine phosphatase, in angiotensin-II signaling. Biochem Biophys Res Commun 2001, 283(5):1061-1068.

29. Siewert JR, Bottcher K, Stein HJ, Roder JD: Relevant prognostic factors in gastric cancer: ten-year results of the German Gastric Cancer Study. Ann Surg 1998, 228(4):449-461.

30. Basak S, Jacobs SB, Krieg AJ, Pathak N, Zeng Q, Kaldis P, Giaccia AJ, Attardi LD: The metastasis-associated gene Prl-3 is a p53 target involved in cell-cycle regulation. Mol Cell 2008, 30(3):303-314.

31. Jiang Y, Liu XQ, Rajput A, Geng L, Ongchin M, Zeng Q, Taylor GS, Wang J: Phosphatase PRL-3 Is a Direct Regulatory Target of TGF $\{$ beta $\}$ in Colon Cancer Metastasis. Cancer Res 2010, 71(1):234-244.

32. Wang H, Vardy LA, Tan CP, Loo JM, Guo K, Li J, Lim SG, Zhou J, Chng WJ, $\mathrm{Ng}$ SB, et al: PCBP1 suppresses the translation of metastasis-associated PRL-3 phosphatase. Cancer Cell 2010, 18(1):52-62.

33. Bell DW, Lynch TJ, Haserlat SM, Harris PL, Okimoto RA, Brannigan BW, Sgroi DC, Muir B, Riemenschneider MJ, lacona RB, et al: Epidermal growth factor receptor mutations and gene amplification in non-small-cell lung cancer: molecular analysis of the IDEAL/NTACT gefitinib trials. J Clin Oncol 2005, 23(31):8081-8092.

34. Lebeau A, Deimling D, Kaltz C, Sendelhofert A, Iff A, Luthardt B, Untch M, Lohrs U: Her-2/neu analysis in archival tissue samples of human breast cancer: comparison of immunohistochemistry and fluorescence in situ hybridization. J Clin Oncol 2001, 19(2):354-363.

35. Daouti S, Li WH, Qian H, Huang KS, Holmgren J, Levin W, Reik L, McGady DL, Gillespie P, Perrotta A, et al: A selective phosphatase of regenerating liver phosphatase inhibitor suppresses tumor cell anchorage-independent growth by a novel mechanism involving p130Cas cleavage. Cancer Res 2008, 68(4):1162-1169.

\section{Pre-publication history}

The pre-publication history for this paper can be accessed here: http://www.biomedcentral.com/1471-2407/11/122/prepub

doi:10.1186/1471-2407-11-122

Cite this article as: Ooki et al:: Therapeutic potential of PRL-3 targeting and clinical significance of $P R L-3$ genomic amplification in gastric cancer. BMC Cancer 2011 11:122.

\section{Submit your next manuscript to BioMed Central and take full advantage of:}

- Convenient online submission

- Thorough peer review

- No space constraints or color figure charges

- Immediate publication on acceptance

- Inclusion in PubMed, CAS, Scopus and Google Scholar

- Research which is freely available for redistribution
Ciomed Central 